\title{
The Acacia controversy resulting from minority rule at the Vienna Nomenclature Section: Much more than arcane arguments and complex technicalities
}

\author{
Gerry Moore, ${ }^{1}$ Gideon F. Smith, ${ }^{2}$ Estrela Figueiredo ${ }^{3}$ Sebsebe Demissew, ${ }^{4}$ Gwilym Lewis, ${ }^{5}$ Brian Schrire,${ }^{5}$ \\ Lourdes Rico, ${ }^{5}$ Abraham E. van Wyk, ${ }^{6}$ Melissa Luckow, ${ }^{7}$ Roberto Kiesling ${ }^{8}$ \& Mario Sousa S. ${ }^{9}$ \\ 1 Brooklyn Botanic Garden, 1000 Washington Avenue, Brooklyn, New York 11225, U.S.A. \\ 2 Office of the Chief Director: Biosystematics Research and Biodiversity Collections, South African National Biodiversity Institute, \\ Private Bag X101, Pretoria 0001 South Africa; \\ Acocks Chair, H.G.W.J. Schweickerdt Herbarium, Department of Plant Science, University of Pretoria, Pretoria, \\ 0002 South Africa; \\ Centre for Functional Ecology, Departamento de Ciências da Vida, Universidade de Coimbra, 3001-455 Coimbra, Portugal \\ 3 Department of Botany, P.O. Box 77000, Nelson Mandela Metropolitan University, Port Elizabeth, 6031 South Africa; \\ Centre for Functional Ecology, Departamento de Ciências da Vida, Universidade de Coimbra, 3001-455 Coimbra, Portugal \\ 4 The National Herbarium, Addis Ababa University, P.O. Box 3434, Addis Ababa, Ethiopia \\ 5 Royal Botanic Gardens, Kew, Herbarium, Library, Art and Archives, Richmond, Surrey, TW9 3AB, U.K. \\ 6 H.G.W.J. Schweickerdt Herbarium, Department of Plant Science, University of Pretoria, Pretoria, 0002 South Africa \\ 7 L. H. Bailey Hortorium, Department of Plant Biology, 228 Plant Sciences, Cornell University, Ithaca, New York 14853, U.S.A. \\ 8 Instituto Argentino de las Zonas Aridas (IADIZA), C.C: 507 (5500) Mendoza, Argentina \\ 9 Instituto de Biología, Universidad Nacional Autónoma de México, Apartado Postal 70-367, 04510 México, D.F. \\ Author for correspondence: Gerry Moore, gerry.moore@gnb.usda.gov
}

\begin{abstract}
The arguments towards resolving the Acacia nomenclatural controversy put forth by Thiele \& al. (2011) are reviewed and rebutted. We argue that a truly pragmatic and, moreover, defensible and equitable alternative to accepting the retypification of Acacia Mill. with a conserved type would be to have the 2006 International Code of Botanical Nomenclature, excluding this retypification, serve as the basis for discussions at the Nomenclature Section of the Melbourne International Botanical Congress in 2011. We, and a large component of the international taxonomic community, and beyond, remain convinced that the minority rule voting procedure used at Vienna on Acacia was inappropriate, resulting in animosity that will without any doubt linger until this situation is rectified. Such a minority rule procedure has never in the history of Nomenclature Sections been implemented before. Exclusion of the Acacia retypification can be achieved through a democratic process by objecting to its inclusion when the printed (2006) Code comes up for adoption at the start of the Nomenclature Section. This is perfectly within the established process that has been used in past Section meetings. The integrity of the Code will suffer permanent damage if the retypification of Acacia Mill. with a conserved type is not removed from the ICBN, especially as it ended up there through a minority decision.
\end{abstract}

Keywords Acacia Mill.; International Botanical Congress; International Code of Botanical Nomenclature; Melbourne; Nomenclature Section

\section{INTRODUCTION}

Over the past eight years a lot of space in the scientific and popular press has been allocated to the controversial retypification of Acacia Mill. with a conserved type at the 2005 International Botanical Congress held in Vienna (see Moore $\&$ al., 2010 and Thiele \& al., 2011 for references). Particularly, the treatment of the proposal to retypify Acacia Mill. with a conserved type as approved, even though it failed to receive majority support from the Vienna Nomenclature Section, has been the subject of considerable criticism (Rijckevorsel, 2006; Smith \& al., 2006; Moore, 2007, 2008; Moore \& al. 2010), with many plant name users not accepting this action. Thiele $\&$ al. (2011) called for a "pragmatic" approach that will maintain the inclusion of Acacia in the International Code of Botanical Nomenclature (ICBN or Code) with a conserved type (McNeill $\&$ al., 2006). We offer an alternative, equitable, pragmatic view that requires the removal of the name Acacia with a conserved type from the Code (Moore \& al., 2010). Exclusion of the Acacia retypification can be achieved through a democratic process by objecting to its inclusion when the printed (2006 or Vienna) Code comes up for adoption at the start of the Nomenclature Section. This is in line with the process that has been used at past Nomenclature Sections. 


\section{PROPOSAL 1584 TO CONSERVE ACACIA WITH A CONSERVED TYPE}

While we believe the proper time to debate the merits of Proposal 1584 on Acacia (Orchard \& Maslin, 2003) was before the Nomenclature Section in Vienna in 2005, we nonetheless respond to points made by Thiele $\&$ al. (2011) that we believe mischaracterize the debate that has so far taken place. The following quotes from Thiele \& al. (2011) summarize their position on Proposal 1584:

"Brummitt (2004) ... stated that two points 'tipped the balance strongly in favour of the proposal.' These were: (1) that the number of affected species in the Australian group was vastly greater than that in any other continent ... and (2) that even if the proposal were rejected, half or more of the Acacia species in Africa (and on the other continents excluding Australia) would need to be recombined into other genera anyway ... [These] two principal arguments accepted by the Committee for Spermatophyta as important factors in their decision ... still stand and have not been countered by the opponents.

"... the original proposal to conserve Acacia with a new type was well within the provisions of Art. 14 of the Code. Conservation of names under Art. 14 has been used many times to avoid a large number of disadvantageous name changes (see, e.g., Hughes, 1997; Choi \& Ohashi, 1998; Greuter \& al., 2001; Ross, 2004). In every case, the decision to support conservation was made principally using the weight-of-numbers and global nomenclatural stability arguments that clearly apply in the Acacia case.

"... the proper basis for objective consideration of this issue should be the simple matter of what best serves the interests of global nomenclatural stability, with the relative numbers of name changes required by the alternative options the prime determining factor."

While the acceptance of the proposals cited by Thiele \& al. (2011), i.e., to conserve the generic names Bossiaea against Platylobium (Ross, 2004), Centauria with a conserved type (Greuter \& al., 2001), Hedysarum with a conserved type (Choi \& Ohashi, 1998), and Leucaena with a conserved type (Hughes, 1997), did result in fewer name changes, it is not true that the "weight-of-numbers" has been given primacy "in every case" to support conservation. Indeed, some proposals to conserve names (and their types) have been rejected even though their acceptance would have resulted in fewer name changes. Such is the case with the proposal to conserve the names Myrica (with a conserved type) and Gale (Verdcourt \& Polhill, 1997; also discussed by Luckow \& al., 2005). With a split of the broadly circumscribed Myrica pending, this proposal would have preserved the name Myrica for approximately 40 extant and 350 fossil species from Africa, the Americas, and Asia, while relegating two extant temperate species to Gale. However, the Committee for Spermatophyta declined to recommend this proposal. Brummitt (1999): "Although the greater number of species occur in the tropics, one temperate species, M. gale, is widespread and ecologically important ... and this name change might offend more people than the transfer of the tropical species. ... The vote probably reflects the view that when there is conflict of interests like this, with fairly well balanced arguments either way, it is best to let simple priority and normal typification decide."

Thiele \& al.'s (2011) statement that the principal arguments used by Brummitt (2004) in his Committee for Spermatophyta report recommending Proposal 1584 have not been countered by its opponents is false. These points have been thoroughly rebutted on numerous occasions. For example, Luckow \& al. (2005):

"We take issue with the primacy of numbers of species alone in this decision. If nomenclatural stability were merely a function of numbers of names and/or species, then our job as taxonomists would be simple. However, we must always weigh the wider impact of nomenclatural changes. How many people are affected by a nomenclatural change? How many floras? What are the numbers of economically important species? What are the economic implications to the countries involved? We think that the impact of the proposed name changes will be greater than assumed if the type of Acacia is changed ... The C[ommittee for] S[permatophyta] pointed out that floras throughout Africa, Asia, and the Americas would have to undergo revision in any case because Senegalia is sympatric with Acacia s.s. [with A. scorpioides as type] throughout much of its range. Although we agree that having to deal with a recircumscribed Acacia in addition to getting to know a new segregate genus will cause confusion in many countries, Proposal 1584 does not avoid this phenomenon, and conservation was never intended to address such peripheral issues ..."

In summary, the "objective" solution (i.e., giving primacy to the number of name changes) advocated by Thiele $\&$ al. (2011) grossly oversimplifies the situation, reducing it to a "name game" in which all names have equal currency. Of course, as Luckow \& al. (2005) make clear, different plant names never have equal currency. Moore (2008), a member of Committee for Spermatophyta when Proposal 1584 was being reviewed, considered giving primacy to the number of name changes as unpersuasive "bean counting" (see also Walker \& Simpson, 2003; Pedley, 2004). An "objective" solution to a problem that ignores the reality of the situation (in this case, the fact that scientific plant names do not have the same level of usage and therefore should not be weighted equally) is no solution at all.

\section{ACTION AT THE NOMENCLATURE SECTION IN VIENNA}

The following from Thiele \& al. (2011) summarizes their position on the action taken on Proposal 1584 at the Nomenclature Section in Vienna in 2005:

“... delegates were asked to vote, as required, to accept or reject the General Committee's decision that the name Acacia be conserved with an Australian type. At the beginning of the Session, prior to the presentation of the reports of the Permanent Committees, the President had proposed, and the meeting accepted, that if a vote was required on a particular item a $60 \%$ majority would be required to overturn any Committee's recommendation (in practice only those of the General Committee). When the Acacia decision was voted on, $54 \%$ of 
votes were cast to reject the General Committee's decision; as this was less than the required $60 \%$ majority, the Committee's decision was not rejected.

"We regard their contention, that the Vienna decision was flawed, to itself be flawed. Arcane arguments concerning complex technicalities of the voting process notwithstanding, we believe that:

"1. the acceptance by the Nomenclature Section in Vienna that a $60 \%$ supermajority would be required to overturn the considered decision of the Committees established expressly to rule on matters pertaining to the Code was appropriate, and helps maintain the stability of the Code;

2. the rules under which voting on the Acacia issue were conducted were made clear to delegates before the vote was taken".

The unusual procedure used for Proposal 1584 allowed the minority opinion of the Nomenclature Section-only $45 \%$ of the votes cast at the Section were in favor of changing the type of Acacia - to effect a change in the Code. Such a minority rule procedure has never in the history of Nomenclature Sections been implemented before. And for good reason, as majority rule is the fundamental principle governing standard rules of procedure. Thus, the Nomenclature Section in Vienna, with its vote on Acacia, violated this most fundamental principle of procedure.

Thiele \& al. (2011) concluded that the procedure used in Vienna on Proposal 1584 was "appropriate" and the arguments of the critics "flawed". However, Thiele \& al. (2011) failed to identify flaws in the critics' (e.g., Rijckevorsel, 2006; Moore, 2007,2008 ) arguments, stating only that they were based on "arcane arguments concerning complex technicalities of the voting process". These criticisms are defenses of the fundamental principle of majority rule. It is disappointing to have such defenses of majority rule dismissed as "arcane arguments concerning complex technicalities".

We find the conclusion reached by Thiele \& al. (2011) that the procedure used at the Nomenclature Section in Vienna "helps maintain the stability of the Code" to be baseless. Indeed the opposite is true. The procedure used at the Nomenclature Section in Vienna on Acacia allowing a change (i.e., instability) to the Code when only a minority support such a change makes the Code less stable as it is much easier to modify under such an approach.

Thiele \& al. (2011) also assert that the procedures used on Acacia were made "clear". However, the proceedings of the Vienna Nomenclature Section suggest otherwise (see Moore \& al., 2010), with the Rapporteur having stated that the proposal was to "reject" but that the vote was "perhaps confusingly, the other way around".

\section{THE NOMENCLATURE SECTION AT MELBOURNE}

The following from Thiele \& al. (2011) summarizes their position on a potential motion by those who are critical of the way in which Proposal 1584 was dealt with in Vienna:
"It is established practice at the beginning of each Congress that a vote be taken to accept the current Code, in its entirety, as the basis for discussion and deliberation. The opponents have signalled that they plan to propose that the Vienna Code be accepted with the Acacia conservation provision excised. ... We believe, however, that this should be done by working within established practice and principles. McNeill \& Turland (2010) suggested that the opponents of the Acacia retypification should prepare, in time for the Melbourne Congress, a formal proposal to conserve Acacia with another type, supported by arguments to justify such a move in the interests of nomenclatural stability. We support this suggestion. However, the opponents of the Vienna decision appear to have no intention to do this, and have chosen instead to attack established process."

Those critical of the way in which Proposal 1584 was handled at the Nomenclature Section in Vienna are not attacking "established process"; rather, they are defending established process. It was the procedure used on Acacia at the Nomenclature Section in Vienna that violated established process, as it permitted a motion to be treated as approved even though a clear majority $(55 \%)$ voted against it. Such a procedure has never been used in any previous Nomenclature Section and is not permitted under any standard system of parliamentary procedure (e.g., Robert \& al., 2000; Sturgis, 2001).

Furthermore, their assertion that we follow McNeill \& Turland's (2010) suggestion and propose to restore the type of Acacia to A. scorpioides would also be contrary to established process. If a proposal to conserve a name goes through all the standard hurdles (i.e., recommendation(s) by the permanent committee(s), recommendation by the General Committee, approval by the Nomenclature Section, ratification by the Congress) then that should be the end of it. Those who may have been opposed to such a proposal should not then go back through the committees to try and undo what was done. Such an approach would be destructive to the process. However, Proposal 1584 on Acacia did not make it through all of the hurdles as it failed to get a majority approval at the Nomenclature Section in Vienna. Since the primary dispute lies not with Proposal 1584 but rather with the procedure used at Vienna that led to the Acacia entry appearing in the printed version of the Vienna Code, it makes perfect sense to challenge this procedure and its result (i.e., the Acacia entry) when the Vienna Code comes up for adoption at the Nomenclature Section in Melbourne. Such challenges while rare are not unprecedented (see Stafleu, 1966).

Contrary to Thiele \& al. (2011) we also fail to see how following the procedure suggested by McNeill \& Turland (2010) would prevent nomenclature from being impacted by pressure groups. First, input from plant name users outside of the nomenclatural community is a good thing. After all, should the plant nomenclatural community in the first instance not serve the interests of the broader community of end users of plant names? Furthermore, under the procedure endorsed by Thiele \& al. and used at the Vienna Nomenclature Section in 2005 , pressure was permitted to be exerted from those outside the plant nomenclatural community. For example, during the Nomenclature Section in Vienna, Richard Brummitt, Secretary of the Committee for Spermatophyta, and Tony Orchard, one 
of the authors of Proposal 1584 (Orchard \& Maslin, 2003), posted dozens of letters, mostly from Australian citizens, in support of Proposal 1584 on several notice boards outside the hall where the Vienna Nomenclature Section was taking place, while correspondence from legume taxonomists and African botanists submitted to the Committee for Spermatophyta was not posted. Furthermore, given the inability to participate in the Nomenclature Section via video- or teleconferencing and the exorbitant cost of attending an International Botanical Congress, serious attempts to influence (i.e., significant attendance) by outside pressure groups seems most unlikely. Indeed the requirement for in-person attendance and high costs to travel to Australia will ensure that much of the global nomenclatural community will not be represented at the Nomenclature Section in Melbourne.

Thiele \& al. (2011) misrepresent the standings of the committees and Nomenclature Section with respect to amending the Code. The various permanent committees have no authority to amend the Code, this authority resting with the International Botanical Congress through its Nomenclature Section (see Division III.1 of the Code). Thus, despite Thiele \& al.'s (2011) assertions, the committees are not "authoritative" with respect to the Code, and their actions with respect to the Code are better characterized as recommendations and not "decisions".

Since it is clear that the decision-making authority with respect to the Code rests with the Nomenclature Section, it is also crucial to understand the role of the majority in effecting decisions. Sturgis (2001): "The most fundamental rule governing voting is that at least a majority vote is required to take an action. ... Jefferson said, 'Until a majority has spoken, nothing has changed.' It is obvious that to permit fewer than a majority to decide for any group would subject the many to the rule of the few, and this would be contrary to the most basic democratic principle. Democratic peoples universally accept decisions by majority vote." Such distinctions may seem arcane and technical to some but they are crucial in understanding the authoritative structure with respect to amending the Code. Failure to make these distinctions is the root cause of this current dispute, and has placed botanical nomenclature in conflict with Sturgis's (2001) most "obvious" conclusion.

\section{PRAGMATISM}

Thiele \& al. (2011) stated "None of the co-authors of this paper has held strong or partisan views on this issue either before, during, or following the Vienna Congress." Of course, the same can be said for many who are now criticizing the actions taken at the Nomenclature Section in Vienna. For example, the first author (Moore), a member of Committee for Spermatophyta when Proposal 1584 was taken up, did not have a strong opinion on Proposal 1584 (see Moore, 2007, 2008) and did not speak on the Acacia matter when it was debated in Vienna. However, many, regardless of their opinions on Proposal 1584, have since spoken up when it became apparent what a colossal breach of protocol the procedure used on the Acacia matter was.
Thiele \& al. (2011) consider their position to accept the procedure used on Acacia and accept A. penninervis as the type of Acacia as "pragmatic". They note that some taxonomists around the world have accepted the actions taken at Vienna and have published numerous new combinations in segregate genera (e.g., Vachellia Wight \& Arn.) in response to the actions taken at Vienna. They warn that such work "will be thrown into confusion" if the actions at Vienna are overturned. However, publications of new combinations cannot be taken as evidence that a given taxonomy or nomenclature has achieved acceptance by the global nomenclatural community because these combinations represent the actions of just a few individuals. If this same logic were applied to Proposal 1584 when it was being considered, the proposal should have been dismissed out of hand since all of the needed combinations in Racosperma Mart. (the correct name for Acacia subg. Phyllodineae when recognized as a genus with Acacia scorpioides as type of Acacia) had already been published, some as early as 1986 (Pedley, 1986).

Furthermore, even acceptance among taxonomists - and the action on Acacia does not have widespread acceptance even within the plant taxonomy community-is not a reasonable gauge that a treatment has been accepted by the global community of users of nomenclature output, since this community is far broader than the taxonomic community. Indeed, it is only when there is acceptance by plant name users outside of taxonomy that it can be said that given changes have been accepted within the global nomenclatural community. And it is here where the Acacia issue has met its most serious resistance. For example, recent field guides and lists for the flora of Africa (e.g., Smit, 2008; Van Wyk \& al., 2008; Grant \& al., 2009; Mannheimer \& Curtis, 2009; Boon 2010; World Agroforestry Center, 2011) and elsewhere (e.g., Rico Arce, 2007) continue to use the name Acacia in the sense of A. scorpioides being the type.

In addition, Thiele $\&$ al. (2011) state that the Acacia case has "also triggered broader criticisms", such as the issues surrounding institutional votes addressed by Smith \& al. (2010). However, the issues of the use and apportionment of institutional votes was being debated among plant taxonomists long before the Acacia controversy developed (see Filgueiras \& al., 1999 for a previous criticism), with Landrum (2010) recently going so far as to propose elimination of institutional votes.

Thiele \& al. (2011) noted "the continuing attacks on the integrity of the process and of some people involved are counterproductive to nomenclatural harmony, to the global nomenclatural consensus, and to the standing of taxonomy in the community" and they express concerns of plant nomenclature falling into "disrepute". However, the discussions since the Vienna Nomenclature Section in 2005 on the procedure used on the Acacia matter (e.g., Smith \& al., 2006; Rijckevorsel, 2006; Moore, 2007, 2008; Moore \& al., 2010) have not attacked established process nor any one person. They have contained criticisms of the way in which the Acacia matter was voted, a procedure we take as a serious deviation away from "established process" that Thiele \& al. (2011) are so concerned about. Indeed, words like "attack" do not help in keeping the dialogue 
dispassionate as advocated by Thiele $\&$ al. (2011). It is true that the dialogue outside of taxonomy has been more "emotive" and does oftentimes break down into "Africa versus Australia and vice versa" stances. However, neither is surprising given that actions taken by minority rule procedures always generate emotive criticism and the taxa affected are heavily represented in Africa and Australia.

Furthermore, we think this concern is overblown. All disciplines in science have debates and these at times can be spirited (or worse), and plant taxonomy and nomenclature are not exceptions. Long ago, Marcus Jones (1912) wrote the following about Edward Lee Greene, with whom Jones frequently disagreed, after Greene's death: "Greene, the pest of systematic botany, has gone and relieved us of his botanical drivel. They say the good that men do lives after them but that the evil is interred with their bones. I suspect that his grave must have been a big one to hold it all." The cladists and pheneticists vigorously debated their methodologies and philosophies, a debate characterized by Hull (1988) as "Systematists at War". Leading up to the Saint Louis Nomenclature Section in 1999, controversial proposals (e.g., BioCode, Names in Current Use, registration) were vigorously debated, an "alternative" I.A.P.T. website was established, and an alternative slate of nominees of officers was developed for key positions in I.A.P.T. and the Bureau of Nomenclature of the International Botanical Congress. At the Nomenclature Section meeting in Saint Louis one participant at the Section was characterized in the official report (Greuter \& al., 2000) as having "exploded" and another described proposals as a "cancer" and a "vampire", this rancor leading Nicolson (1999) to suggest "that we ought not act like blood-thirsty enemies". Compared to these examples, the Acacia controversy is quite mild, none of the critics suggesting grave sizes for anyone, declaring war, exploding, or characterizing the controversy as a disease or a reanimated corpse. Nor have the critics proposed changes in any officers, thus not taking the, perhaps tongue in cheek, advice of some botanists upset about the action taken on Acacia at the Vienna Nomenclature Section: "We say impeach the current rulers ...!" (Hammel \& al., 2006).

\section{CONCLUSION}

Over the past $100+$ years there have been thousands of votes to amend rules of the Code and add names as conserved or rejected to the Code. Only once-the vote on Acacia at the Vienna Nomenclature Section in 2005-was a motion treated as approved when the vote at the Nomenclature Section registered a clear majority (55\%) disapproving of the change. Our position that the minority rule procedure used at Vienna on Acacia was inappropriate is supported by the opinions of two parliamentarians (Nancy Sylvester, Larry Winn) and two legal scholars (Glazewski \& Rumble, 2009).

Thiele \& al.'s (2011) conclusion that the action taken in Vienna on Acacia was "appropriate" (and presumably one to be used again) actually takes the dialogue on this issue backwards. Even McNeill \& Turland (2010), who maintain that the action taken on Acacia at Vienna was valid, acknowledged that the procedure used on Acacia was "probably not one to be adopted again". Furthermore, Landrum (2010) has made proposals to amend Division III of the Code that would bar the minority rule procedure used at Vienna on Acacia from being used again and ensure that motions are not passed without a $60 \%$ majority in the affirmative. Given all of this, it is hard to view Thiele $\&$ al.'s acceptance of the action taken at Vienna on Acacia as a pragmatic position. Furthermore, it could lead to a repeat performance of what took place with Acacia.

A truly pragmatic solution to this controversy is for the matter to be debated and voted on as outlined by Moore \& al. (2010) at the Nomenclature Section in Melbourne in 2011. Having a minority ruling determine the future use of the name Acacia (or any name or issue for that matter) sits uncomfortably with many taxonomists and other users of plant names. It cannot be in anyone's interests to wish to maintain this situation. There is a large plant name user community who will never accept the inclusion of Acacia with a conserved type in the Code based on what occurred at Vienna. As Moore \& al. (2010) noted: “... the [Acacia] controversy will no doubt continue well beyond Melbourne, if this situation is not rectified there."

The following is from Peter Raven's address to the Nomenclature Section in Saint Louis in 1999 (Greuter \& al., 2000):

"When we set up codes of nomenclature ... we are basically putting out a system of naming plants that has no teeth, no penalties, no down side; a system that simply depends on the willingness of all dealing with plants and their names, to accept the decisions made by a majority [our emphasis] in order to perfect the system so that it may go on into the future."

However, the "decision" at the Vienna Nomenclature Section on Acacia was not "made by a majority". And this is at the root of the noncompliance in the plant name user community with respect to Acacia.

Thiele \& al. (2011) recommended that the "world should move on". However, moving on now would be tantamount to a fire-fighter leaving the scene of the fire and going someplace else to put out a fire where none exists. The greatest danger botanical nomenclature has with respect to falling into the "disrepute" that Thiele \& al. (2011) are concerned about is not debating the Acacia controversy but rather endorsing the unprecedented minority rule procedure used on Acacia at the Vienna Nomenclature Section in 2005.

\section{口 LITERATURE CITED}

Boon, R. 2010. Pooley's trees of eastern South Africa: A complete guide. Durban: Flora and Fauna Publications Trust.

Brummitt, R.K. 1999. Report of the Committee for Spermatophyta: 48. Taxon 48: 359-371.

Brummitt, R.K. 2004. Report of the Committee for Spermatophyta: 55 [Proposal 1584 on Acacia]. Taxon 53: 826-829.

Choi, B.H. \& Ohashi, H. 1998. (1377) Proposal to conserve the name Hedysarum (Leguminosae: Papilionoideae) with a conserved type. Taxon 47: 877.

Filgueiras, T.S., Davidse, G., Kirkbride, J.H., Chiang, F., Rueda, R., \& Zuloaga, F.O. 1999. Should small herbaria have voting rights? Taxon 48: 767-770.

Glazewski, J. \& Rumble, O. 2009 A rose is a rose but is an Acacia 
an Acacia? Global administrative law in action. Acta Juridica 9: 374-394.

Grant, R., Thomas, V. \& Moll, E. 2009. Sappi tree spotting: Cape. Johannesburg: Jacana Media.

Greuter, W., McNeill, J., Hawksworth, D.L. \& Barrie, F.R. 2000. Report on botanical nomenclature, Saint Louis 1999. Englera 20: $1-253$.

Greuter, W., Wagenitz, G., Agababian, M. \& Hellwig, F.H. 2001. (1509) Proposal to conserve the name Centaurea (Compositae) with a conserved type. Taxon 50: 1201-1205.

Hamel, B., Grayum, M. \& Zamora, N. 2006. Germane Literature. Cutting Edge 13(3). http://www.mobot.org/mobot/research/edge/ jul06/jul06lit.shtml (accessed 16 April 2011).

Hull, D. 1988. Science as a process. Chicago: University of Chicago Press.

Hughes, C. 1997. (1297) Proposal to conserve the name Leucaena (Leguminosae) with a conserved type. Taxon 46: 355-356.

Jones, M. 1912. Greene. Contr. W. Bot. 15: 225-229.

Landrum, L.R. 2010. (199-202) Four proposals for Division III, Provisions for the Governance of the Code. Taxon 59: 1616.

Luckow, M. \& 36 co-authors. 2005. Acacia: The case against moving the type to Australia. Taxon 54: 513-519.

Mannheimer, C. \& Curtis, B. (eds). 2009. Le Roux and Müller's field guide to the trees and shrubs of Namibia. Windhoek: Macmillan Education Namibia.

McNeill, J., Barrie, F.R., Burdet, H.M., Demoulin, V., Hawksworth, D.L., Marhold, K., Nicolson, D.H., Prado, J., Silva, P.C., Skog, J.E., Wiersema, J.H. \& Turland, N.J. 2006. International code of botanical nomenclature (Vienna Code): Adopted by the Seventeenth International Botanical Congress, Vienna, Austria, July 2005. Regnum Vegetabile 146. Ruggell, Liechtenstein: Gantner.

McNeill, J. \& Turland, N. 2010. The conservation of Acacia with A. penninervis as conserved type. Taxon 59: 613-616.

Moore, G. 2007. The handling of the proposal to conserve the name Acacia at the 17th International Botanical Congress - an attempt at minority rule. Bothalia 37 : 109-118.

Moore, G. 2008. Action on the proposal to conserve the name Acacia at the Nomenclature Section of the XVII International Botanical Congress in Vienna: Did the ayes have it? Linnean 24(2): 16-120.

Moore, G., Smith, G.F., Figueiredo, E., Demissew, S., Lewis, G., Schrire, B., Rico, L. \& Van Wyk, A.E. (coordinating authors; 61 other authors). 2010. Acacia, the 2011 Nomenclature Section in Melbourne, and beyond. Taxon 59: 1188-1195.

Nicolson, D.H. 1999. Report on the General Assembly. Taxon 48: 785-792.
Orchard, A.E. \& Maslin, B.R. 2003. (1584) Proposal to conserve the name Acacia (Leguminosae: Mimosoideae) with a conserved type. Taxon 52: 362-363.

Pedley, L. 1986. Derivation and dispersal of Acacia (Leguminosae), with particular reference to Australia, and the recognition of Senegalia and Racosperma. Bot. J. Linn. Soc. 92: 219-254.

Pedley, L. 2004. Another view of Racosperma. Acacia Group Newslett. 90: 3-5.

Rico Arce, M. de L. 2007. A checklist and synopsis of American species of Acacia (Leguminosae: Mimosoideae). México, D.F., Mexico: Comis. Nac. Conocim. Uso Biodivers. (CONABIO).

Rijckevorsel, P. van. 2006. Acacia: What did happen at Vienna? Anales Jard. Bot. Madrid 63: 107-110.

Robert, H.M., Robert, S.C., Robert, H.M., Evans, W.J., Honemann, D.H. \& Balch, T.J. 2000. Robert's rules of order, newly revised, ed. 10. Cambridge, Massachusetts: Persus.

Ross, J.H. 2004. (1649) Proposal to conserve the name Bossiaea against Platylobium (Leguminosae). Taxon 53: 1075-1076.

Smit, N. 2008. Field guide to the acacias of South Africa. Pretoria: Briza Publications.

Smith, G.F., Figueiredo, E. \& Moore, G. 2010. Who amends the International code of botanical nomenclature? Taxon 59: 930-934.

Smith, G.F., Van Wyk, A.E., Luckow, M. \& Schrire, B. 2006. Conserving Acacia Mill. with a conserved type. What happened in Vienna? Taxon 55: 223-225.

Stafleu, F. 1966. Nomenclature Section. Tenth International Botanical Congress, Edinburgh 1964. Regnum Vegetabile 44. Utrecht: International Bureau for Plant Taxonomy and Nomenclature.

Sturgis, A. 2001. The standard code of parliamentary procedure, ed. 4. New York: McGraw-Hill.

Thiele, K.R., Funk, V., Iwatsuki, K., Morat, P., Peng, C-I., Raven, P.H. \& Seberg, O. 2011. The controversy over the retypification of Acacia Mill. with an Australian type-a pragmatic view. Taxon 60: 194-198.

Van Wyk, B., Van Wyk, P. \& Van Wyk, B.-E. 2008. Photo guide to trees of southern Africa, ed. 2. Pretoria: Briza Publications.

Verdcourt, B. \& Polhill, R. 1997. (1291-1292) Proposals to conserve the names Myrica and Gale (Myricaceae) with conserved types. Taxon 347-348.

Walker, J. \& Simpson, J. 2003. An alternative view to ICBN Proposal 1584 to conserve the name Acacia (Leguminosae: Mimosoideae) with a conserved type. Newslett. Austral. Syst. Bot. Soc. 117: 17-21.

World Agroforestry Centre. 2011. Various databases; in particular Botanical nomenclature database, http://www.worldagroforestry .org/our_products/databases (accessed 1 March 2011). 